\title{
Complete Molar Pregnancies with a Coexisting Fetus: Pregnancy Outcomes and Review of Literature
}

Roxanna A. Irani, MD PhD ${ }^{1}$ (1) Kerry Holliman, MD ${ }^{2}$ Michelle Debbink, MD PhD ${ }^{3}$ Lori Day, MD Krista Mehlhaff, $\mathrm{DO}^{5}$ Lisa Gill, $\mathrm{MD}^{6}$ Cara Heuser, $\mathrm{MD} \mathrm{MSCl}^{7}$ Alisa Kachikis, MD MSc ${ }^{8}$ Kristine Strickland, MD ${ }^{9}$ Justin Tureson, $\mathrm{DO}^{10}$ Jessica Shank, MD ${ }^{11}$ Rachel Pilliod, MD ${ }^{12}$ Chitra lyer, MD ${ }^{13}$ Christina S. Han, MD20

\footnotetext{
${ }^{1}$ Department of Obstetrics, Gynecology and Reproductive Sciences, Division of Maternal Fetal Medicine, University of California San Francisco, San Francisco, California

${ }^{2}$ Austin Maternal-Fetal Medicine, Austin, Texas

${ }^{3}$ Department of Obstetrics and Gynecology, Division of Maternal Fetal Medicine, University of Utah, Salt Lake City, Utah

${ }^{4}$ Obstetrix Medical Group, Beacon Memorial Hospital, Division of Maternal Fetal Medicine, South Bend, Indiana

${ }^{5}$ Department of Obstetrics and Gynecology, Division of Maternal Fetal Medicine, Walter Reed National Military Medical Center, Bethesda, Maryland

${ }^{6}$ Department of Obstetrics, Gynecology, and Women's Health, Division of Maternal Fetal Medicine, University of Minnesota, Minneapolis, Minnesota

7 Department of Obstetrics and Gynecology, Division of Maternal Fetal Medicine, Intermountain Healthcare and University of Utah, Salt Lake City, Utah
}

Address for correspondence Roxanna A. Irani, MD, PhD, Department of Obstetrics, Gynecology \& Reproductive Sciences, University of California San Francisco, $55016^{\text {th }}$ Street, $7^{\text {th }}$ floor, Box 0132, San

Francisco, CA, 94143 (e-mail: roxanna.irani@ucsf.edu).

${ }^{8}$ Department of Obstetrics and Gynecology, Division of MaternalFetal Medicine, University of Washington, Seattle, Washington

9 Prevea Health, Maternal Fetal Medicine, Green Bay, Wisconsin

10 Department of Obstetrics and Gynecology, Naval Readiness and Training Command, Twentynine Palms, Twentynine Palms, California

${ }^{11}$ Department of Obstetrics and Gynecology, Division of Gynecologic Oncology, Tulane University School of Medicine, New Orleans, Louisiana

${ }^{12}$ Department of Obstetrics and Gynecology, Oregon Health \& Science University, Division of Maternal Fetal Medicine, Portland, Oregon

${ }^{13}$ Obstetrix Medical Group of Texas, Fort Worth, Texas

AJP Rep 2022;12:e96-e107.
Abstract
Keywords
- antenatal complications
- multiple gestation
- twin pregnancy
- molar pregnancy
- gestational trophoblastic neoplasia
- maternal morbidity

Objective The objective of the study was to review the obstetric outcomes of complete hydatidiform molar pregnancies with a coexisting fetus (CHMCF), a rare clinical entity that is not well described.

Materials and Methods We performed a retrospective case series with pathologyconfirmed HMCF. The cases were collected via solicitation through a private maternalfetal medicine physician group on social media. Each contributing institution from across the United States $(n=9)$ obtained written informed consent from the patients directly, obtained institutional data transfer agreements as required, and transmitted the data using a Health Insurance Portability and Accountability Act of 1996 (HIPAA) compliant modality. Data collected included maternal, fetal/genetic, placental, and delivery characteristics. For descriptive analysis, continuous variables were reported as median with standard deviation and range.

Results Nine institutions contributed to the 14 cases collected. Nine (64\%) cases of CHMCF were a product of assisted reproductive technology and one case was received

October 20, 2020 accepted after revision October 8, 2021
DOI https://doi.org/ 10.1055/a-1678-3563 ISSN 2157-6998.

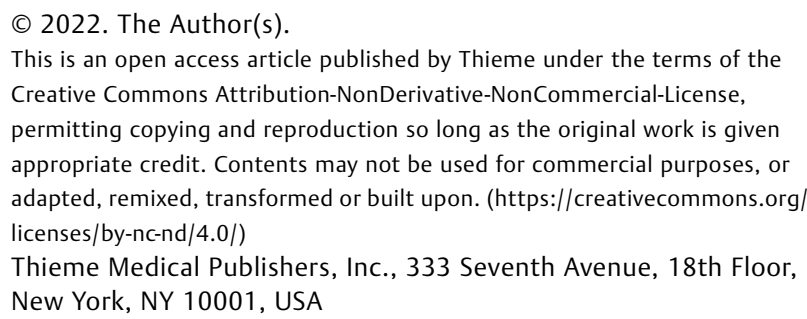
appropriate credit. Contents may not be used for commercial purposes, or adapted, remixed, transformed or built upon. (https://creativecommons.org/ licenses/by-nc-nd/4.0/) Thieme Medical Publishers, Inc., 333 Seventh Avenue, 18th Floor, New York, NY 10001, USA 
trizygotic. The median gestational age at diagnosis was 12 weeks and 2 days ( 9 weeks-19 weeks and 4 days), and over half were diagnosed in the first trimester. The median human chorionic gonadotropin (hCG) at diagnosis was $355,494 \mathrm{mIU} / \mathrm{mL}$ $(49,770-700,486 \mathrm{mIU} / \mathrm{mL})$. Placental mass size universally enlarged over the surveillance period. When invasive testing was performed, insufficient sample or no growth was noted in $40 \%$ of the sampled cases. Antenatal complications occurred in all delivered patients, with postpartum hemorrhage $(71 \%)$ and hypertensive disorders of pregnancy (29\%) being the most frequent outcomes. Delivery outcomes were variable. Four patients developed gestational trophoblastic neoplasia.

Conclusion This series is the largest report of obstetric outcomes for CHMCF to date and highlights the need to counsel patients about the severe maternal and fetal complications in continuing pregnancies, including progression to gestational trophoblastic neoplastic disease.

\section{Key Points}

- CHMCF is a rare obstetric complication and may be associated with the use of assisted reproductive technology.

- Universally, patients with CHMCF who elected to manage expectantly developed antenatal complications.

- The risk of developing gestational trophoblastic neoplasia after CHMCF is high, and termination of the pregnancy did not decrease this risk.

Ultrasonographic evidence of an enlarged multicystic placenta with a normal-appearing fetus is an uncommon finding during routine surveillance of pregnancy. The differential diagnoses of these features include partial hydatidiform molar pregnancy with a coexisting fetus (HMCF) or complete HMCF (CHMCF), placental mesenchymal dysplasia (PMD), placental infarcts, chorioangioma, subchorionic hematoma, placental cysts, and placenta accreta spectrum (PAS) disorders. In the context of an otherwise normal-appearing fetus, the obstetrical course and postpartum follow-up of these conditions are vastly different ( - Table $\mathbf{1}$ ).

In the case of a CHMCF, it is especially important to have an accurate diagnosis. This rare condition, affecting 20,000 to 100,000 pregnancies, ${ }^{1,2}$ is fraught with potential maternal complications, such as hemorrhage, preeclampsia, and preterm delivery of the viable coexisting fetus. Persistent gestational trophoblastic neoplasia (GTN) is also seen more frequently in $\mathrm{CHMCF}$, when compared with a single complete mole, and termination of the pregnancy has not been shown to decrease this risk. ${ }^{1,3,4}$

Although there have been large case series reported on CHMCF, they have focused mainly on outcomes as they relate to the GTN associated with this condition. ${ }^{1,3,4}$ In these reports, the use of artificial reproductive technology (ART) was either not reported or, when reported, did not account for a majority of cases (13\%). An increased use of ART over the past several decades may affect the prevalence of CHMCF and so obstetricians should be cognizant of this condition and its associated ante-, intra-, and postpartum risks. When an isolated complete molar pregnancy is noted, evacuation of the premalignant molar tissue is recommended. However, in the case of a CHMCF, a woman may elect to be managed expectantly to prolong the pregnancy. Here, we provide the first multicenter series of CHMCF reporting detailed accounts of the diagnosis, pregnancy outcomes, and postpartum follow-up, as well as a review of existing literature, to aid in the counseling of this at-risk cohort of pregnant women.

\section{Materials and Methods}

A retrospective analysis of women with CHMCF pregnancies was performed. The cases were collected via solicitation through a private maternal-fetal medicine physician group on social media. Each contributing institution from across the United States $(n=9)$ obtained written informed consent from the patient(s) directly, obtained institutional data transfer agreements as requested, and transmitted the data using a Health Insurance Portability and Accountability Act of 1996 (HIPAA) compliant modality.

Electronic records were reviewed and the following data were identified: maternal characteristics (age, gravidity, parity, prepregnancy body mass index, race, and prior maternal comorbidities); mode of conception; gestational age at diagnosis; human chorionic gonadotropin (hCG) at diagnosis; zygosity of the pregnancy; screening assessments (including laboratory and imaging); antenatal genetics (procedure type, results, and timing); and size of placental mass as measured by prenatal ultrasonography. Maternal complications including vaginal bleeding, hyperthyroidism, and hypertensive disorders of pregnancy were noted. The timing, mode, and indication for delivery, as well as the estimated blood loss or complications of delivery or procedure were recorded. Postnatal confirmation of genetics and 
Table 1 Comparison of the clinical findings of placental mesenchymal dysplasia (PMD), complete hydatidiform mole (CHM), and partial hydatidiform mole (PHM)

\begin{tabular}{|c|c|c|c|}
\hline & PMD & $\mathrm{CHM}$ & PHM \\
\hline Ultrasound findings & \multicolumn{3}{|c|}{$\begin{array}{l}\text { Enlarged multicystic placenta with anechoic regions (“moth-eaten” appearance) } \\
\text { Findings widely distributed, large edematous villi }\end{array}$} \\
\hline Fetus $^{18}$ & $\begin{array}{l}\text { - Can be unremarkable } \\
\text { - FGR (50\%) } \\
\text { - IUFD or neonatal death } \\
\text { (43\%) } \\
\text { - Consider BWS findings: } \\
\text { macroglossia, omphalo- } \\
\text { cele, genitourinary ab- } \\
\text { normalities, overgrowth, } \\
\text { polyhydramnios }\end{array}$ & $\begin{array}{l}\text { - Coexisting fetus can be } \\
\text { unremarkable }\end{array}$ & $\begin{array}{l}\text { - May be structurally abnor- } \\
\text { mal triploid fetus }\end{array}$ \\
\hline Pathology & $\begin{array}{l}\text { - Enlarged stem villi with } \\
\text { loose connective tissue } \\
\text { and cisternlike formations } \\
\text { - Absent trophoblastic } \\
\text { changes }\end{array}$ & $\begin{array}{l}\text { - Hydropic swelling of villi } \\
\text { - Diffuse trophoblastic hyper- } \\
\text { plasia } \\
\text { - Diffuse and marked tropho- } \\
\text { blastic atypia at the molar } \\
\text { implantation site }\end{array}$ & $\begin{array}{l}\text { - Focal trophoblastic hyper- } \\
\text { plasia } \\
\text { - Marked variability in the size } \\
\text { and degree of swelling, and } \\
\text { cavitation of the villi } \\
\text { - Marked scalloping and } \\
\text { prominent stromal tropho- } \\
\text { blastic inclusion in the villi } \\
\text { - Focal and mild trophoblastic } \\
\text { atypia at molar implantation } \\
\text { site }\end{array}$ \\
\hline $\begin{array}{l}\text { Associated maternal } \\
\text { morbidities }\end{array}$ & None identified & $\begin{array}{l}\text { - GTN } \\
\text { - Preeclampsia } \\
\text { - Choriocarcinoma }\end{array}$ & $\begin{array}{l}\text { 1. GTN } \\
\text { 2. Preeclampsia } \\
\text { 3. Choriocarcinoma }\end{array}$ \\
\hline Cytogenetics & $\begin{array}{l}\text { - } \text { Normal karyotype }(89 \%) \\
\text { - } 46 \text { XX (78\%), } 46 \text { XY (22\%) } \\
\text { - BWS: confirmed or sus- } \\
\text { pected }(23 \%)^{20}\end{array}$ & $\begin{array}{l}46 \mathrm{XX} \text { : haploid } 23 \mathrm{X} \text { sperm } \\
\text { duplicates its own chromo- } \\
\text { somes } 21,22 \\
\text { - } 46 \mathrm{XY} \text { : ova penetrated by } 2 \\
\text { sperm (dispermy), } 46 \mathrm{XY}^{23}\end{array}$ & $\begin{array}{l}\text { - Triploidy: extra haploid } \\
\text { sperm }^{4}\end{array}$ \\
\hline Clinical presentation & $\begin{array}{l}\text { No definitive clinical charac- } \\
\text { teristics, but may be associat- } \\
\text { ed with preterm } \\
\text { labor, secondary to amniotic } \\
\text { fluid abnormalities }\end{array}$ & $\begin{array}{l}\text { - Vaginal bleeding } \\
\text { - Size greater than dates } \\
\text { - Theca lutein cysts } \\
\text { - Hyperemesis } \\
\text { - Preeclampsia } \\
\text { - Hyperthyroidism } \\
\text { - Pulmonary edema } \\
\text { - Respiratory distress }\end{array}$ & $\begin{array}{l}\text { - Commonly diagnosed after } \\
\text { missed or incomplete abor- } \\
\text { tion, based on pathology }\end{array}$ \\
\hline
\end{tabular}

Abbreviations: BWS, Beckwith-Wiedemann syndrome; CHM, complete hydatidiform mole; FGR, fetal growth restriction; GTN, gestational trophoblastic neoplasia; IUFD, intrauterine fetal demise; PHM, partial hydatidiform mole; PMD, placental mesenchymal dysplasia.

pathology, postpartum follow-up, including hCG trend and time to nadir, diagnosis of GTN, and subsequent treatments were identified.

Fetal and neonatal outcomes recorded included any structural anomalies noted prenatally, intrauterine fetal growth restriction, intrauterine or neonatal fetal demise, and neonatal birthweight.

\section{Statistical Analysis}

For descriptive analysis, continuous variables were reported as median with standard deviation and range. Categorical variables were reported as proportions.

\section{Results}

After solicitation via social media, nine institutions were able to obtain patient consent and contributed 14 cases in total.
Clinical characteristics of the patients are delineated in -Table 2.

Of the cases presented here, $64 \%$ were the product of ART: $29 \%$ ovulation induction alone, $21 \%$ ovulation induction with intrauterine insemination, and $14 \%$ in vitro fertilization. Only five cases (36\%) were due to spontaneous conception. The median gestational age at diagnosis was 12 weeks and 2 days (9 weeks-19 weeks and 4 days), with 64\% $(n=9)$ diagnosed in the first trimester and the remaining diagnosed by 20 weeks of gestation. Upon either diagnosis or suspicion of diagnosis, all patients were referred to a maternal-fetal medicine specialist, who was involved in the remainder of the pregnancy. The median hCG at diagnosis was 355,494 $\mathrm{mIU} / \mathrm{mL}(49,770-700,486 \mathrm{mIU} / \mathrm{mL})$. The largest dimension of the placental mass at the time of diagnosis varied, ranging from 3.5 to $12 \mathrm{~cm}$. The size of the placental mass universally enlarged over the antenatal surveillance period. Antenatal 
Table 2 Patient characteristics and comorbidities

\begin{tabular}{|l|l|l|l|l|l|l|}
\hline Case no. & Age $(\mathrm{y})$ & G/P & Conception & BMI & Race/ethnicity & Comorbidities \\
\hline $\mathbf{1}$ & 30 & $2 / 1001$ & OI/GnTP/IUI & 20.8 & Caucasian & None \\
\hline $\mathbf{2}$ & 27 & $1 / 0$ & OI/CC & 26.7 & Caucasian & PCOS, seizure disorder on Lamictal \\
\hline $\mathbf{3}$ & 36 & $1 / 0$ & OI/CC/IUI & 30.6 & Caucasian & Lupus on Plaquenil \\
\hline $\mathbf{4}$ & 32 & $2 / 1001$ & Spontaneous & 23.0 & Caucasian & None \\
\hline $\mathbf{5}$ & 26 & $2 / 0010$ & Spontaneous & 34.0 & Caucasian/Asian & Anxiety, depression \\
\hline $\mathbf{6}$ & 29 & $2 / 1001$ & OI/GnTP & 22.6 & Caucasian & Chronic HTN \\
\hline $\mathbf{7}$ & 27 & $1 / 0$ & OI/CC & 36.0 & Caucasian & None \\
\hline $\mathbf{8}$ & 35 & $2 / 1001$ & Spontaneous & 31.6 & White & h/o Roux-en-Y, anemia, h/o gestational HTN \\
\hline $\mathbf{9}$ & 28 & $8 / 2052$ & OI/GnTP & 28.2 & White & Migraine, PCOS with infertility \\
\hline 10 & 28 & $3 / 1011$ & Spontaneous & 19.4 & Arab-American & h/o 2nd trimester IUFD (19 wk) \\
\hline 11 & 32 & $4 / 2012$ & Spontaneous & 21.0 & White & h/o bilateral PE, h/o 2nd trimester IUFD (16 wk) \\
\hline 12 & 38 & $2 / 1001$ & IVF & 22.9 & Asian & seizures on levetiracetam and lamotrigine \\
\hline 13 & 34 & $3 / 1011$ & COH/IUI & 24.0 & Caucasian & None \\
\hline 14 & 33 & $1 / 0$ & IVF & 21.0 & Asian & Asthma \\
\hline
\end{tabular}

Abbreviations: BMI, body mass index; CC, clomiphene citrate; $\mathrm{COH}$, controlled ovarian hyperstimulation; GnTP, gonadotropin; h/o, history of; HTN, hypertension; IUI, intrauterine insemination; IUFD, intrauterine fetal demise; IVF, in vitro fertilization; OI, ovulation induction; PCOS, polycystic ovarian syndrome; PE, pulmonary embolism.

genetic analysis was performed in 10 of the 14 cases. Insufficient sample or no growth of the sample from either amniocentesis $(n=5)$ or chorionic villous sampling (CVS; $n=5$ ) was a common finding, occurring in $40 \%$ of cases sampled $(n=4)$.

In the reported dizygotic $\mathrm{CHMCF}$ pregnancies, no malformations were identified. The one case of trizygotic CHMCF pregnancy had a complete mole, a coexisting structurally normal fetus, and a partial molar pregnancy with cystic hygroma and complex congenital heart defect.

Antenatal management and complications are described in -Table 3. Universally, patients with $\mathrm{CHMCF}$ experienced some form of antenatal complication, including vaginal bleeding $(10 ; 71 \%)$, hypertensive disorder of pregnancy $(4$; $28.9 \%$ ), pulmonary edema ( $1 ; 0.7 \%)$, and hyperthyroidism ( 1 ; $0.7 \%$ ). Of the patients with vaginal bleeding, 4 of 10 (40\%) required admission and/or transfusion. The case of hyperthyroidism required medical treatment with antithyroid medications and ultimately resulted in termination of pregnancy.

The majority of patients opted for expectant management $(64.3 \%, n=9)$, and the average GA at delivery was 28 weeks and 3 days ( 16 weeks and 6 days to 34 weeks and 5 days). One patient developed an early-onset HELLP-like syndrome at 16 weeks and 6 days, which prompted treatment with dilation and evacuation (D\&E). Another patient experienced persistent vaginal bleeding throughout the pregnancy, resulting in preterm labor and vaginal delivery at 20 weeks and 2 days. A third patient developed hemorrhage and chorioamnionitis and was delivered at 17 weeks and 5 days. Two patients who opted for expectant management also had postpartum hemorrhage, with one of these requiring a hysterectomy due to bleeding after emergent delivery at 24 weeks and 5 days. She subsequently required treatment for metastatic GTN (-Table 3).

None of the patients who opted for termination of pregnancy had complications from the procedure, including hemorrhage (-Table 3 ). One of the patients who underwent termination of pregnancy developed pulmonary edema at 20 weeks 0 days at the time of diagnosis.

GTN was diagnosed in $28.6 \%$ of patients $(n=4)$, with two $(2 / 8 ; 25 \%)$ from the expectant management group and two $(2 / 5 ; 40 \%)$ from the termination group. The two cases of GTN from the termination group were International Federation of Gynecology and Obstetrics (FIGO) stages 1 and 3, while the two cases from the expectant management were FIGO stages 3 and 4 . All were treated with intravenous (IV) methotrexate. One patient also received leucovorin, and the patient with FIGO stage 4 disease also received IV dactinomycin. Two of these patients were also noted to have a nadir in their hCG levels by day 56 postdelivery/evacuation.

\section{Discussion}

In this series, we analyzed the patient characteristics, diagnosis, pregnancy complications, and resultant obstetric outcomes of 14 pregnancies complicated by CHMCF. Complete hydatidiform moles (CHM) are generally homozygous 46 , XX and result from duplication of the haploid genome of a single sperm following fertilization of an ovum in which the maternal chromosomes are lost during meiosis, or due to postzygotic diploidization in a triploid conception. ${ }^{5}$ A multizygotic pregnancy consisting of a partial or complete HMCF is a rare complication of pregnancy, and the available cases series to date focus on GTN risk, instead of obstetrical risk. ${ }^{6} \mathrm{~A}$ multicystic placental mass on ultrasound imaging is 


\begin{tabular}{|c|c|c|c|c|c|c|c|c|c|c|}
\hline 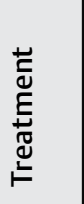 & $\begin{array}{l}\stackrel{x}{E} \\
\geq\end{array}$ & 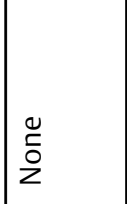 & 㫕 & 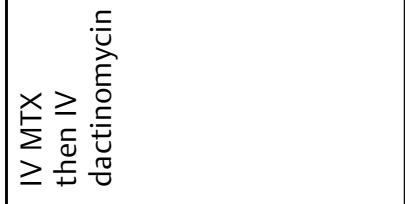 & $\begin{array}{l}0 \\
\text { on } \\
z\end{array}$ & $\mid \begin{array}{l}\mathscr{\nu} \\
\check{0} \\
z\end{array}$ & 㫕 & $\begin{array}{l}0 \\
\tilde{\nu} \\
z\end{array}$ & 㫕 & 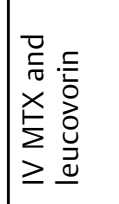 \\
\hline 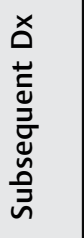 & 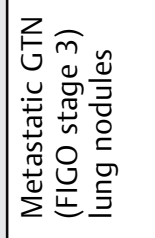 & $\begin{array}{l}u \\
\check{\nu} \\
\text { z }\end{array}$ & 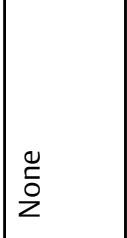 & 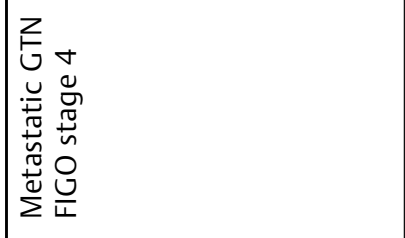 & $\mid \begin{array}{l}0 \\
\tilde{0} \\
z \\
z\end{array}$ & $\mid \begin{array}{l}0 \\
\check{0} \\
\check{z}\end{array}$ & $\begin{array}{l}\ddot{\nu} \\
\text { Oे }\end{array}$ & $\begin{array}{l}\mathscr{\nu} \\
\text { Oे }\end{array}$ & 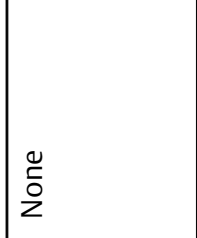 & 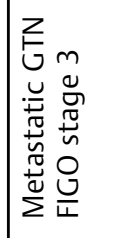 \\
\hline 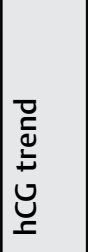 & 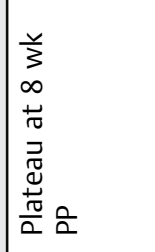 & 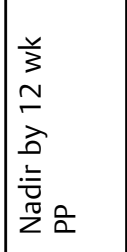 & 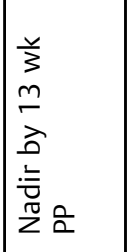 & 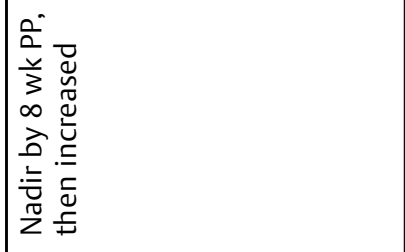 & 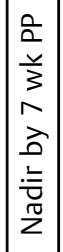 & 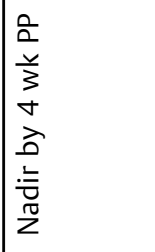 & 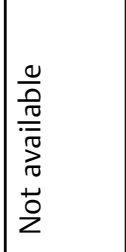 & 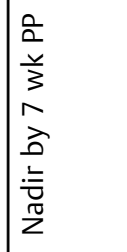 & 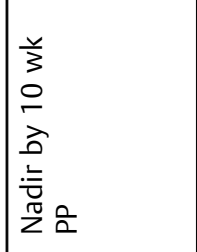 & 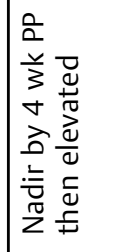 \\
\hline 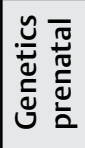 & $\begin{array}{l}\underset{x}{x} \\
x \\
0 \\
0\end{array}$ & $\mid \begin{array}{l}0 \\
\tilde{\tilde{z}} \\
z\end{array}$ & $\stackrel{\widetilde{\sim}}{\sim}$ & \begin{tabular}{|l}
0 \\
$\check{\tilde{\sigma}}$ \\
$z$
\end{tabular} & $\mid \begin{array}{l}0 \\
\tilde{\Sigma} \\
z\end{array}$ & $\mid \begin{array}{l}0 \\
\tilde{0} \\
z\end{array}$ & \begin{tabular}{|l}
0 \\
$\check{\tilde{\sigma}}$ \\
$z$
\end{tabular} & 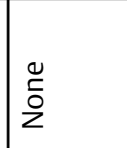 & $\begin{array}{l}0 \\
\check{\tilde{z}} \\
z\end{array}$ & $\mid \begin{array}{l}0 \\
\check{\tilde{\sigma}} \\
z\end{array}$ \\
\hline $\begin{array}{l}\overrightarrow{\vec{E}} \\
\vec{\Xi} \\
\vec{\Psi}\end{array}$ & 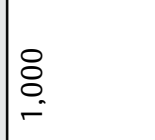 & $\stackrel{\circ}{\circ}$ & 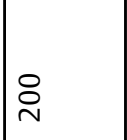 & 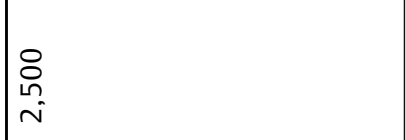 & $\stackrel{\stackrel{\sim}{\sim}}{\rightleftharpoons}$ & $\stackrel{\circ}{\stackrel{n}{N}}$ & $\stackrel{8}{\circ}$ & 总 & 오ํ & $\stackrel{\circ}{\stackrel{\circ}{N}}$ \\
\hline 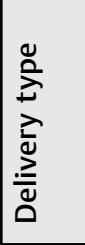 & 岗 & 忿 & 岗 & 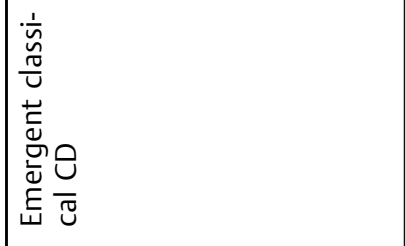 & $\begin{array}{l}u \\
\varnothing \\
\Delta\end{array}$ & 忿 & $\begin{array}{l}\frac{O}{U} \\
\frac{\pi}{\tilde{n}} \\
\tilde{U} \\
\frac{\pi}{U}\end{array}$ & 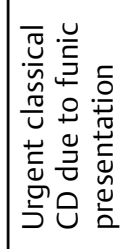 & in & \begin{tabular}{|l}
$\infty$ \\
$\varnothing$
\end{tabular} \\
\hline 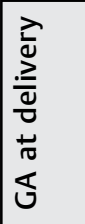 & $\begin{array}{l}0 \\
0 \\
0 \\
0 \\
0 \\
0 \\
\frac{0}{3} \\
0 \\
0\end{array}$ & 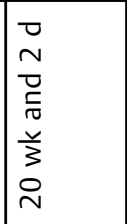 & $\begin{array}{l}0 \\
m \\
m \\
\frac{n}{c} \\
\frac{0}{0} \\
\frac{n}{3} \\
m \\
m\end{array}$ & 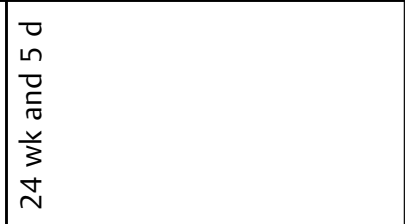 & 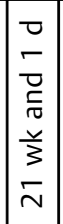 & $\begin{array}{l}0 \\
\text { nn } \\
0 \\
\\
0 \\
0 \\
\frac{1}{3} \\
5 \\
m\end{array}$ & 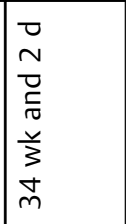 & 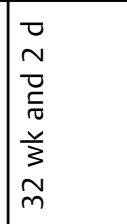 & 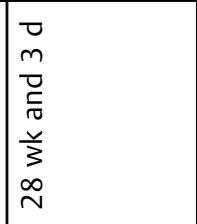 & $\begin{array}{l}\frac{n}{3} \\
\underline{n}\end{array}$ \\
\hline 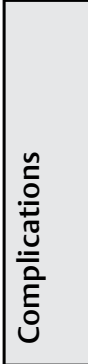 & 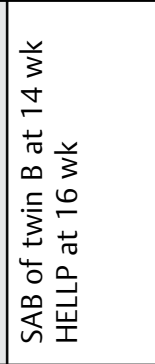 & 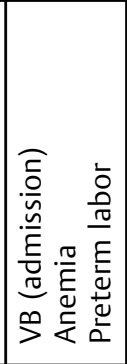 & 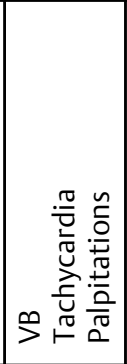 & 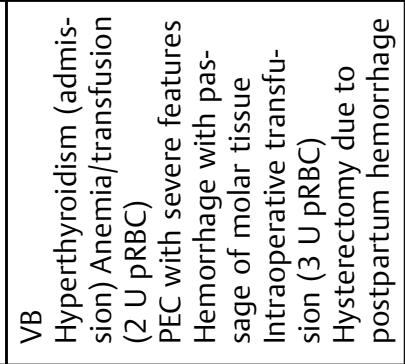 & 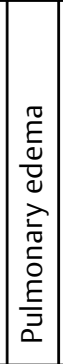 & 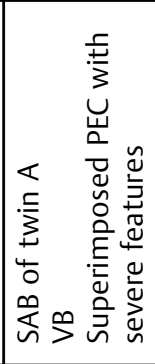 & 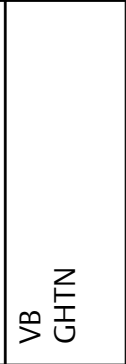 & 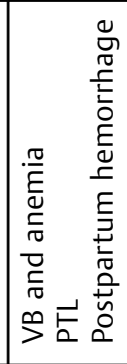 & 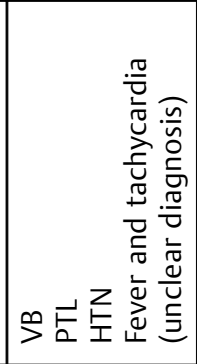 & 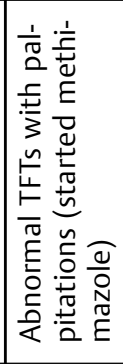 \\
\hline 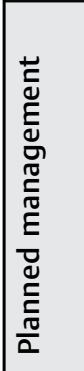 & 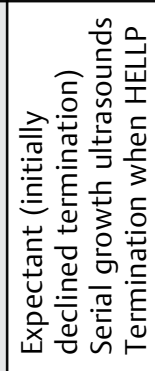 & 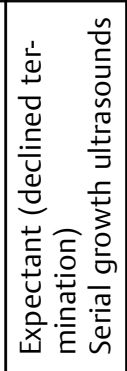 & $\mid$ & 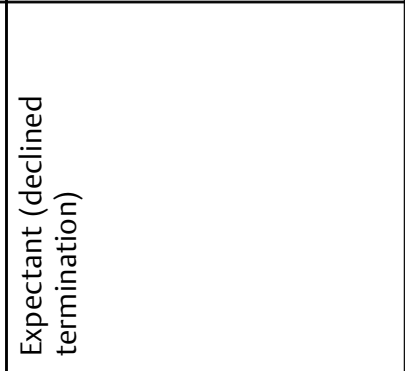 & 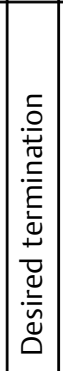 & 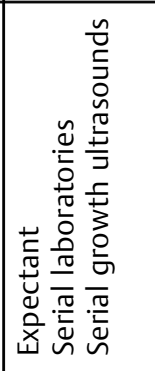 & 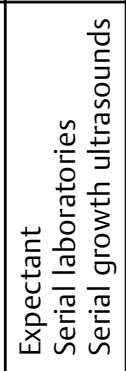 & 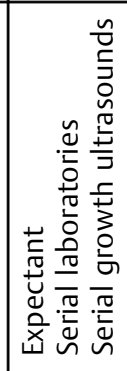 & 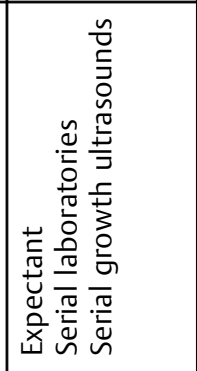 & 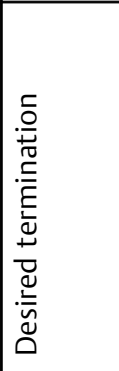 \\
\hline 岕 & - & $\sim$ & $m$ & $\nabla$ & in & 0 & $r$ & $\infty$ & $a$ & $\circ$ \\
\hline
\end{tabular}




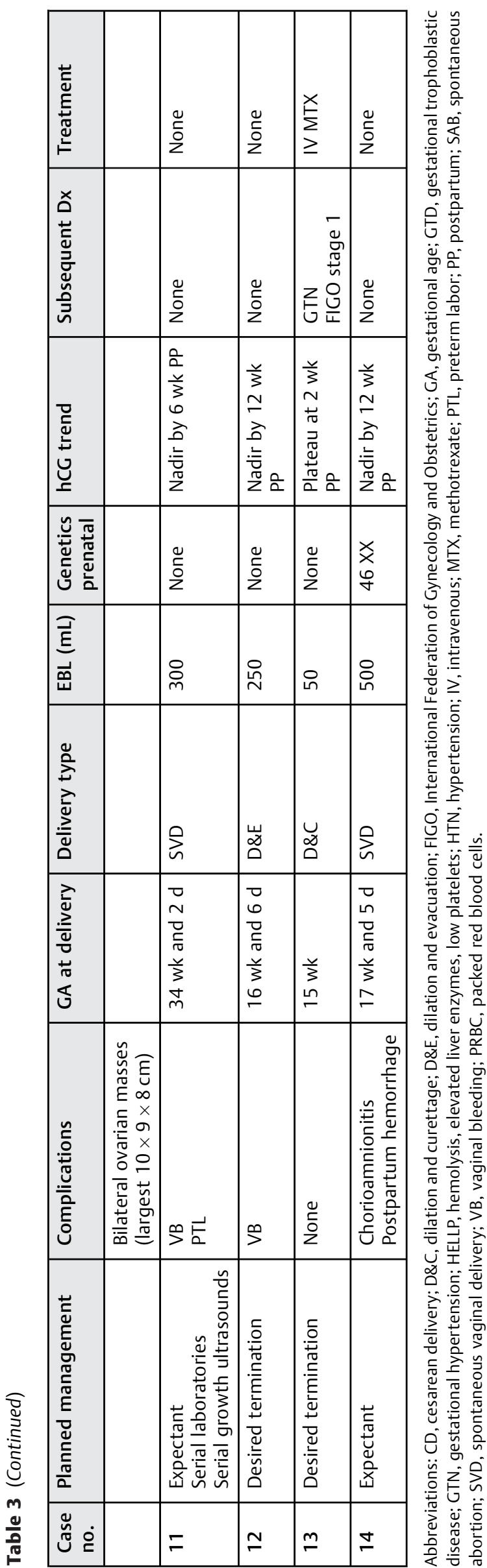

typically seen in the first trimester (- Figs. 1-4 and - Supplementary Video S1) and should trigger a referral to a maternal-fetal medicine specialist for further imaging and potential diagnostic testing. With improved ultrasound technology and rising rates of ART, ${ }^{7}$ HMCF diagnoses may be made earlier and more frequently, highlighting the importance of data accrual on the course and outcome of these pregnancies. $^{8}$

The differential diagnosis of a multicystic placenta with a coexisting fetus can be broad, as a multicystic placenta can represent a hydropic abortus, chromosomal abnormalities, digynic triploid conceptions, PMD, or a molar pregnancy. These distinct diagnoses have varying complications, potential outcomes, and management strategies. The ability to differentiate between these diagnoses is key for optimal counseling and management. Pregnancies with these sonographic findings should be evaluated by and co-managed with a maternal-fetal medicine subspecialist. Maternal serum $\alpha$-fetoprotein (MSAFP) measurements and $\beta$ hCG measurements are helpful in confirming the diagnosis. The levels in our case series are comparable to previous case series with $\beta$ hCG levels greater than $150,000 \mathrm{mIU} / \mathrm{mL}$. Previous cases series have suggested a plateau of $\beta$ hCG levels in the second trimester and that a failure to reach a plateau was associated with increased risk of adverse pregnancy outcomes. ${ }^{7}$

Ultrasound, $\beta$ hCG, and MSAFP may not provide sufficient data to differentiate between possible diagnoses; thus, invasive diagnostic testing may be necessary for genetic analysis. Amniocentesis can be utilized to evaluate for a triploidy in the coexistent fetus or the placenta as this would be suggestive of a partial hydatidiform mole. Previous literature has suggested CVS of the suspected molar tissue as an alternative via molecular genotyping and segregation analysis of paternal and placental alleles, as absence of maternal alleles can confirm a diandrogenic complete mole..$^{9-11}$ Our series is the first to report common use of invasive testing in CHMCF, and to show that $40 \%$ of invasive procedures may yield no growth or insufficient sample in these cases. Preprocedural counseling regarding invasive testing should include this potential outcome of testing.

Furthermore, CHM is well recognized to have the potential for local invasion and distant spread. It has also been suggested that persistent trophoblastic disease and metastatic GTN are more pervasive with a multifetal gestation with concurrent mole, up to $30 \%$ increased risk. ${ }^{12} \beta$ hCG and molar volumes have been used to predict malignant potential, although this is an area where more research is needed. ${ }^{12}$

The presence of a CHMCF creates complications for both the mother and the fetus with the clinical course frequently complicated by vaginal bleeding, preeclampsia, hyperemesis gravidarum, hyperthyroidism, and gestational trophoblastic disease. ${ }^{10}$ Our case series describes the complication rates in a modern cohort, particularly highlighting the significance of morbid vaginal bleeding and hypertensive disorders of pregnancy in these women. A recent systemic review reported similar findings of a high rate of perinatal morbidities. ${ }^{13}$

Including the cases reported in this series, 16 reports of trizygotic pregnancy with two coexisting fetuses and a 
e102 Complete Molar Pregnancies with a Coexisting Fetus Irani et al.

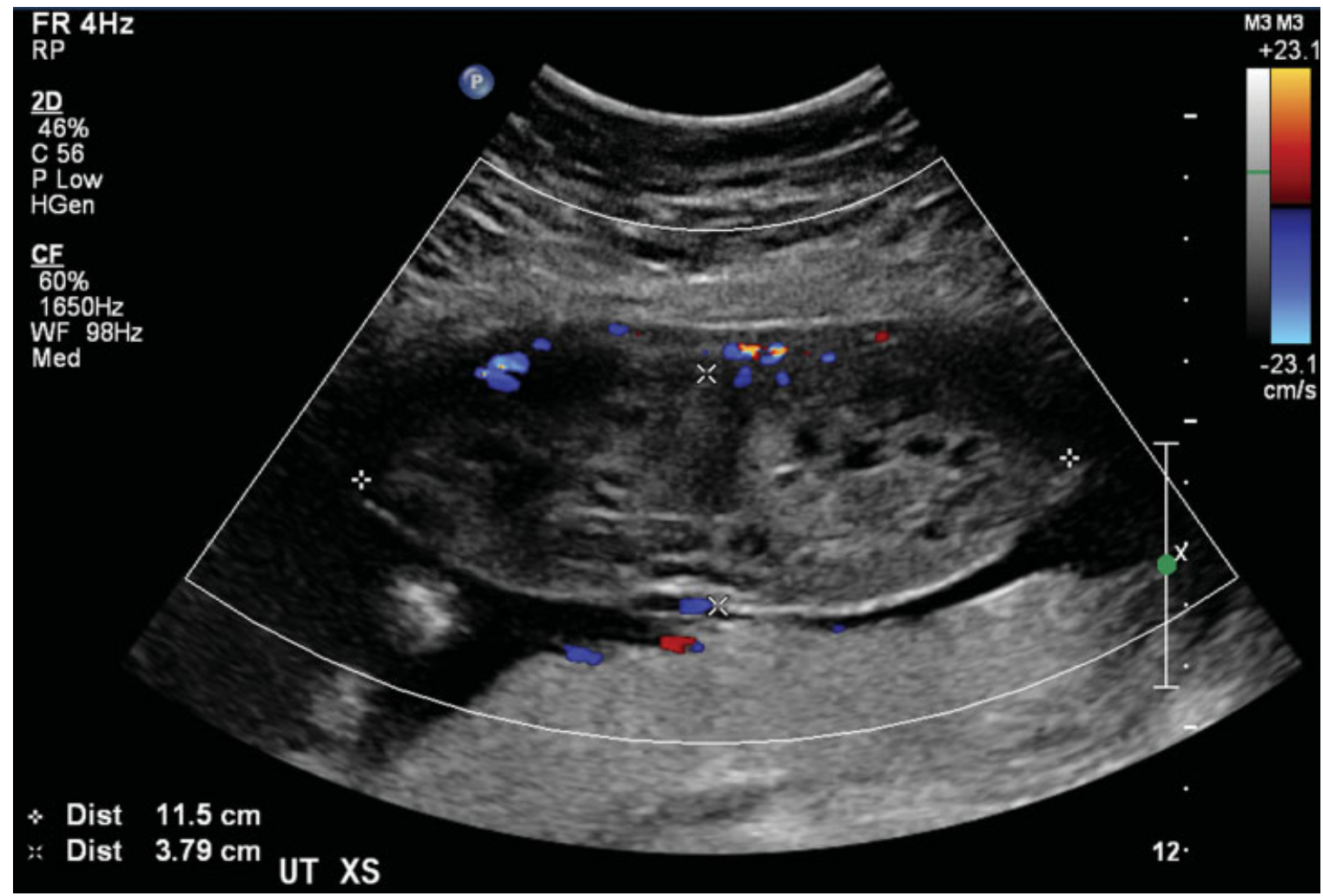

Fig. 1 Dizygotic pregnancy with large complete hydatidiform molar tissue and normal placenta.

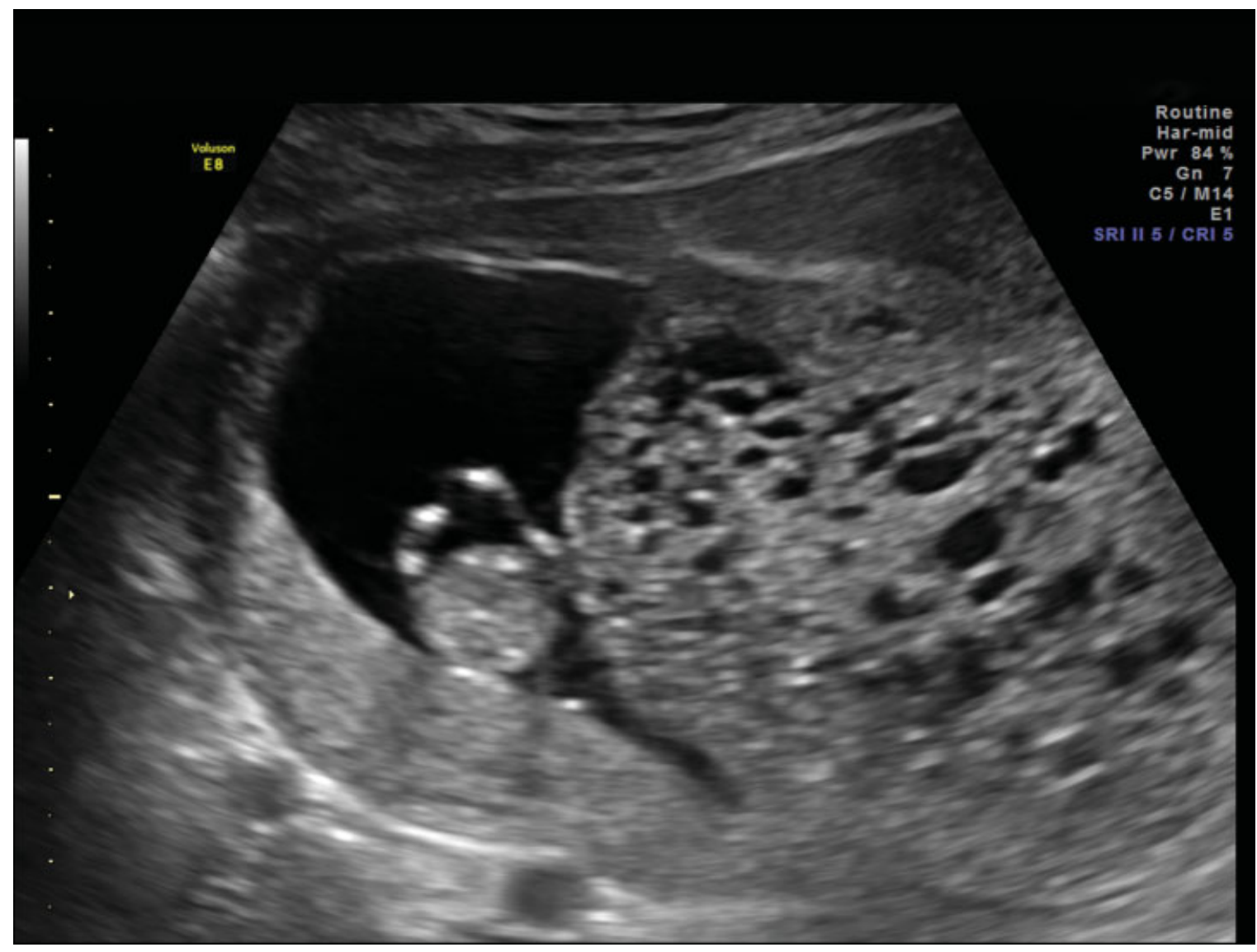

Fig. 2 Dizygotic pregnancy at 11 weeks and 4 days with complete hydatidiform molar tissue and viable fetus. 


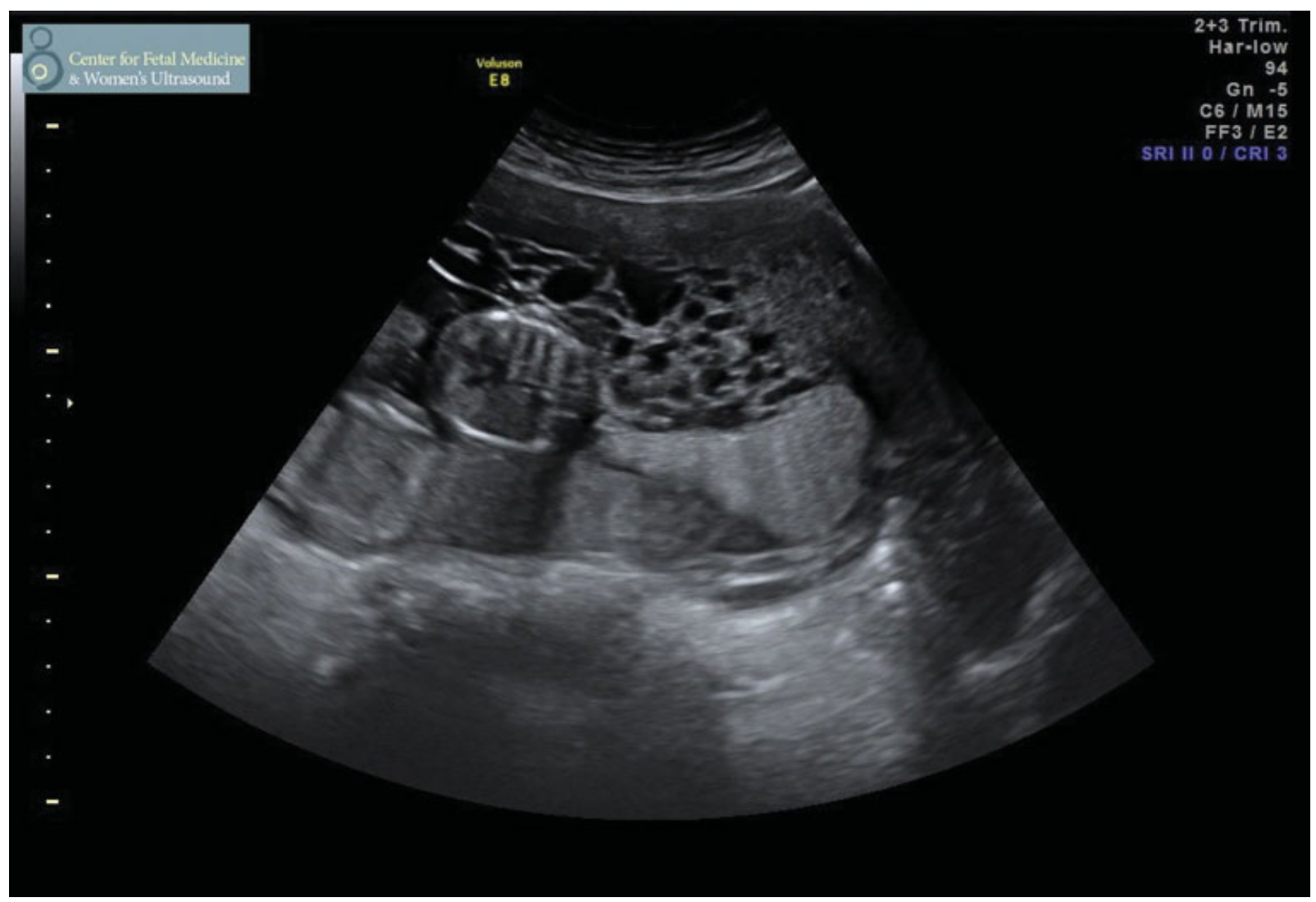

Fig. 3 Dizygotic pregnancy with complete hydatidiform molar tissue and abutting normal placenta from a viable fetus.
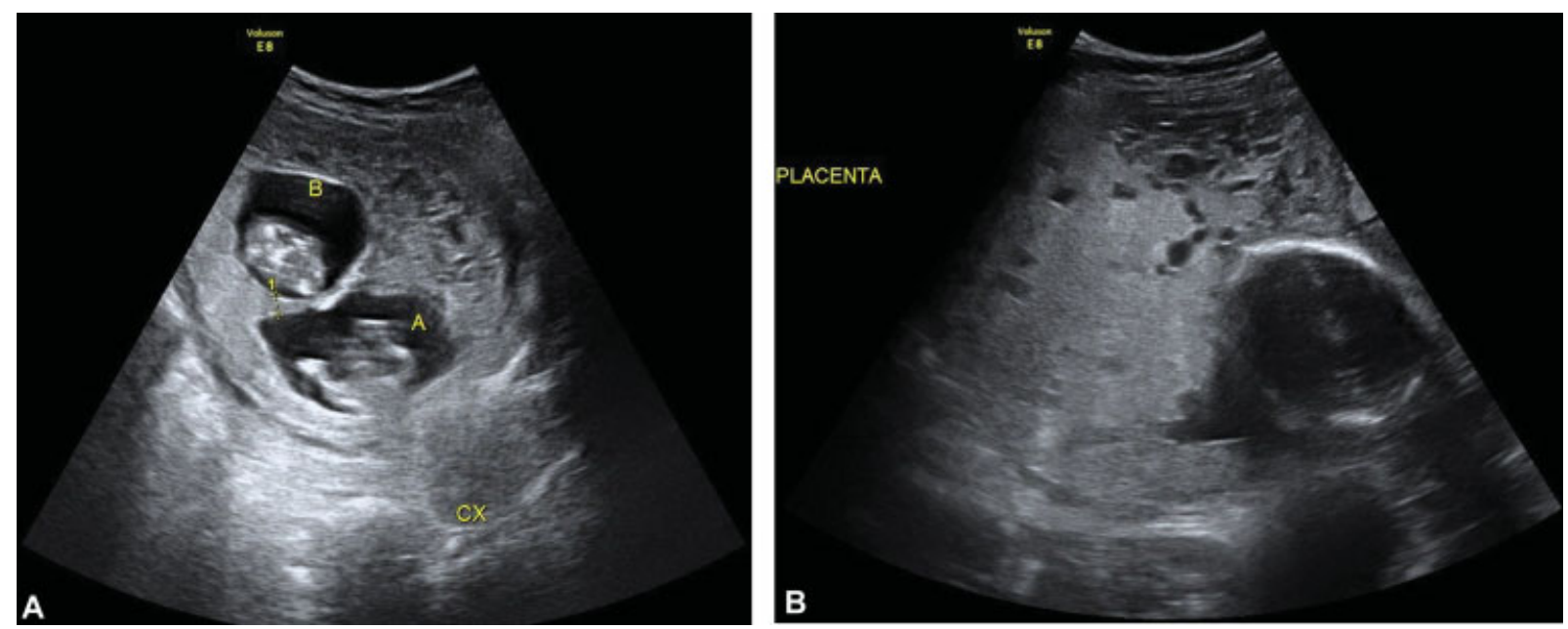

Fig. 4 Trizygotic pregnancy at (A) 11 weeks and 5 days with complete hydatidiform molar tissue and at (B) 24 weeks with the head of twin B and complete hydatidiform molar tissue.

complete mole have been reported ( - Table 4).$^{5,9,10,14-16}$ Of the 16 cases, $87.5 \%$ have been pregnancies conceived with ovulation induction medications. The clinical course of these pregnancies shows that vaginal bleeding is very common, presenting in $59 \%$ of the cases reported to date.

The risk of GTN is higher in the presence of a complete mole compared with a partial mole (14-20\% compared with $1-5 \%) .{ }^{5}$ GTN can include invasive mole, choriocarcinoma, placental site trophoblastic tumor, and epithelioid tropho- blastic tumor. The series reported here suggests that the incidence of GTN may be higher in CHMCF than in other molar pregnancies, with $28.6 \%$ of patients in this series having GTN. Although the group who opted for termination had a high percentage of GTN, the FIGO stages appeared to be lower. This highlights the importance of counseling regarding the risk of distant metastatic disease with expectant management and need for close patient follow-up postdelivery of patients with CHMCF. 


\begin{tabular}{|c|c|c|c|c|c|c|c|c|c|c|}
\hline 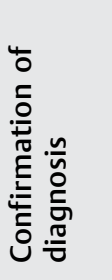 & 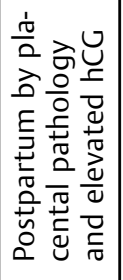 & 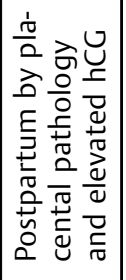 & 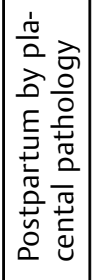 & 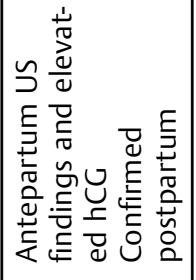 & 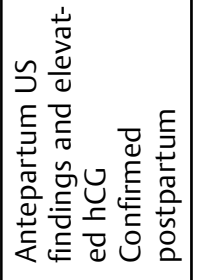 & 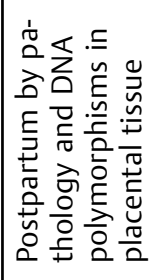 & 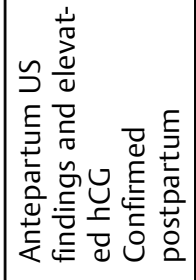 & 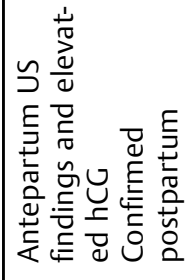 & 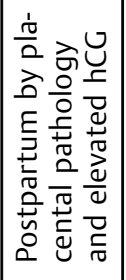 & 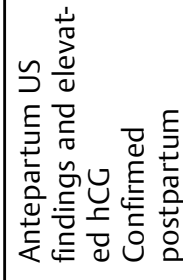 \\
\hline 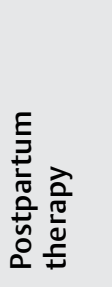 & 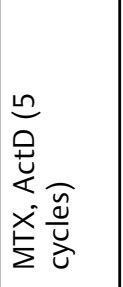 & $\frac{\pi}{z}$ & $\frac{k}{z}$ & $\frac{k}{z}$ & 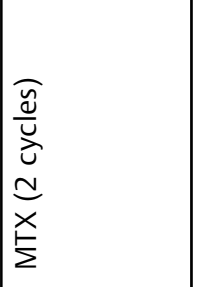 & 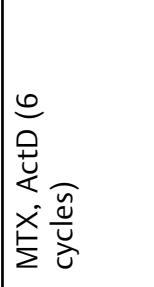 & 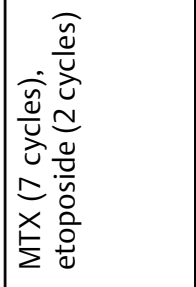 & $\frac{\pi}{z}$ & $\frac{\pi}{z}$ & $\frac{\ll}{z}$ \\
\hline ㄴ & $\stackrel{\circ}{z}$ & 占 & $\stackrel{\circ}{z}$ & $\stackrel{0}{z}$ & 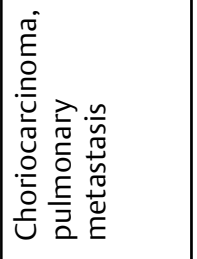 & 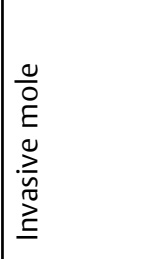 & 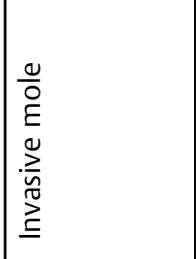 & z & in & in \\
\hline 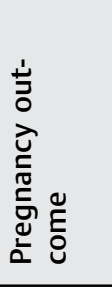 & 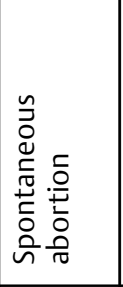 & 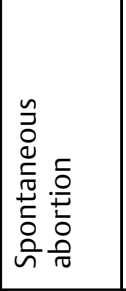 & 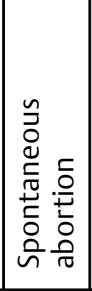 & 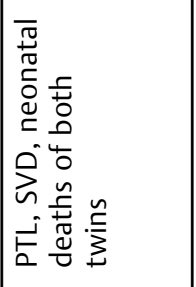 & 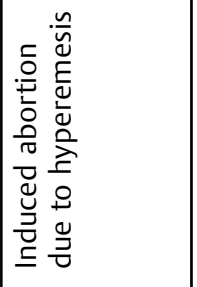 & 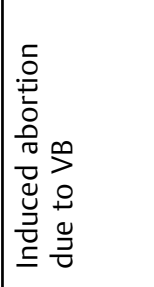 & 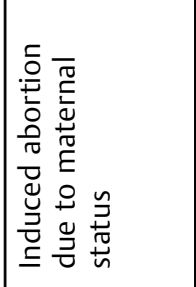 & 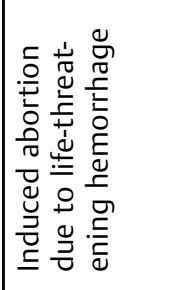 & 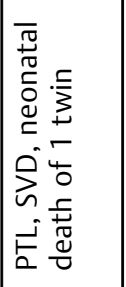 & 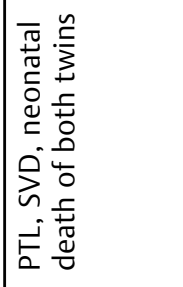 \\
\hline 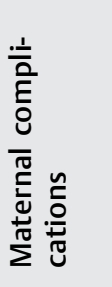 & 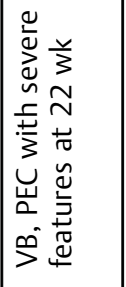 & $\stackrel{\infty}{>}$ & $\stackrel{\infty}{>}$ & $\stackrel{\rho}{>}$ & 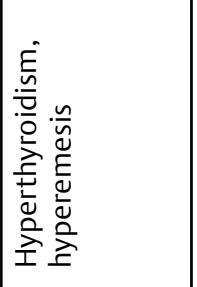 & $\stackrel{\rho}{>}$ & 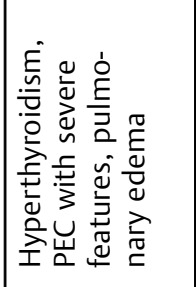 & 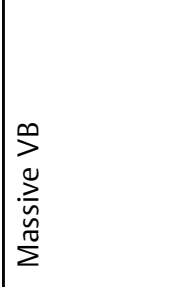 & $\begin{array}{l}0 \\
\tilde{0} \\
z\end{array}$ & $\stackrel{\rho}{\rho}$ \\
\hline 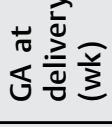 & $\approx$ & 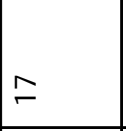 & $\stackrel{9}{\square}$ & $\stackrel{\Xi}{\sim}$ & 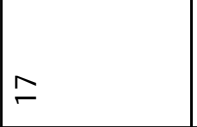 & $\stackrel{\sim}{\sim}$ & $\approx$ & $\stackrel{0}{\circ}$ & $\stackrel{m}{ }$ & $\stackrel{\Xi}{\sim}$ \\
\hline 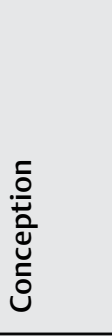 & 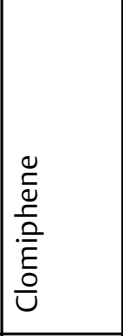 & 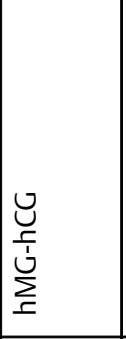 & 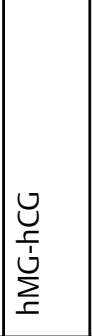 & $\frac{5}{v}$ & 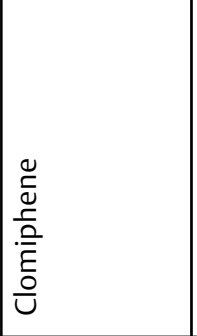 & 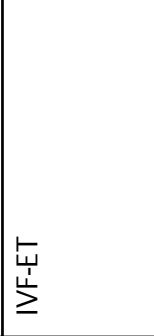 & 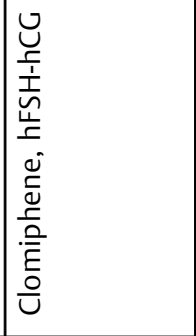 & 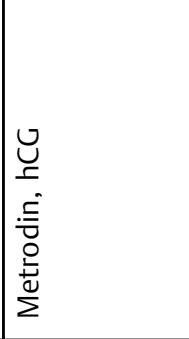 & 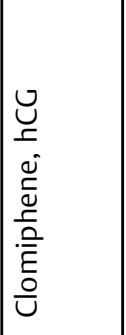 & 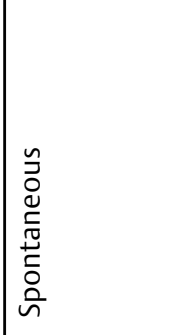 \\
\hline 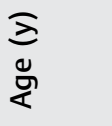 & $\stackrel{\dddot{N}}{\sim}$ & $\dot{m}$ & $\stackrel{\ddagger}{\sim}$ & $\bar{m}$ & $\stackrel{\llcorner}{\sim}$ & $\bar{m}$ & $\ddot{\sim}$ & $\bar{m}$ & $\bar{m}$ & 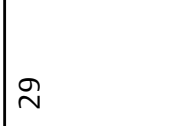 \\
\hline 剤 & 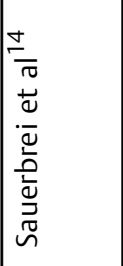 & 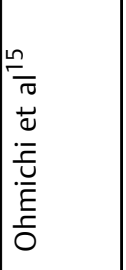 & 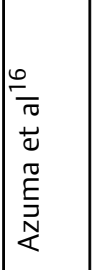 & 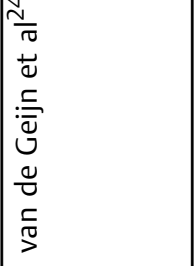 & $\begin{array}{l}\frac{n}{0} \\
\frac{n}{\pi} \\
\frac{0}{0} \\
\frac{0}{0} \\
\frac{0}{\pi} \\
\frac{\pi}{n}\end{array}$ & 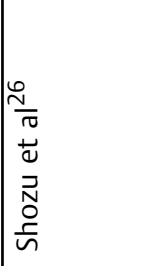 & 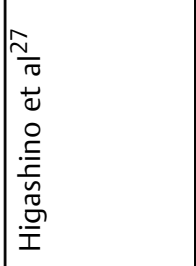 & 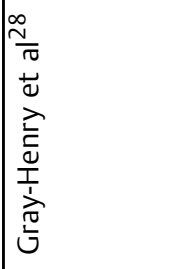 & 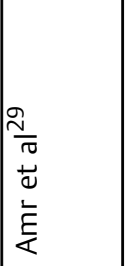 & 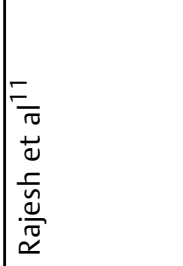 \\
\hline
\end{tabular}




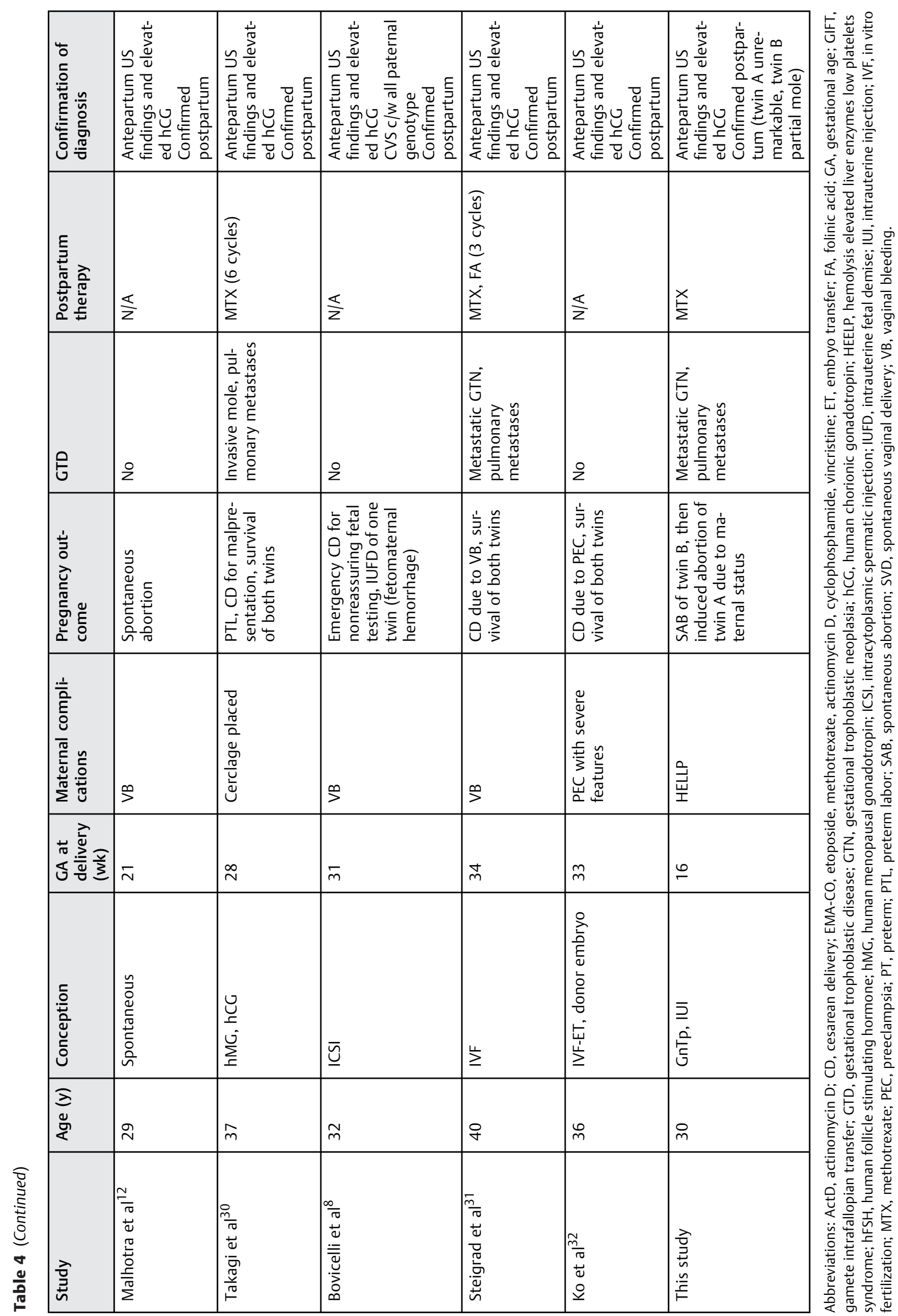


A recent meta-analysis by Albright et al states that the risk of GTN in patients with normalization of $\beta$ HCG by day 56 , or after 8 weeks, is $0.35 \%$ for complete mole and $0.03 \%$ for partial mole. ${ }^{17}$ This is in contrast to our series, where $50 \%$ of CHMCF patients who developed GTN had a nadir of $\beta$ hCG by day 56 . More studies and collaborative efforts are warranted to further evaluate the possibility of additional risk of GTN. It is well known that CHMCF carries a much greater risk of pregnancy complication if expectant management is performed, with increased risk of vaginal bleeding, preeclampsia, and preterm labor, but the increased risk of CHMCF may also carry a significantly increased risk of GTN, and this may indicate a longer period of serial $\beta$ hCG measurements and surveillance and should prompt extensive patient counseling. ${ }^{1,3,4}$

One of the greatest strengths of our study is that this is the largest series to date for obstetric data in CHMCF and includes a wide geographic region. Additionally, the use of social media to engage physicians from across the country is a novel approach to transmural collaborations, instead of individual reports of complex cases. Once connected, the physicians were able to use a standardized collection of data across institutions, giving more uniformity to the data for comparison. Although our study has many strengths, it is limited by the potential of selection bias, and given its retrospective recall of cases, the worst cases with the poorest outcomes could have been collected and reviewed. Furthermore, the observational nature of the study cannot truly compare the management protocols, as is often the case with rare disorders.

\section{Conclusion}

Overall, our findings demonstrate that it is possible to manage CHMCF expectantly but requires shared decisionmaking while factoring in maternal antepartum and peripartum risks, as well as increased risk of subsequent metastatic GTN. This case series can serve as a tool for engaging in full counseling of patients about the varied and potentially significant outcomes of CHMCF gestations, which are likely to be on the rise with the increasing use of ART.

Additionally, it is also important to consider innovative methods of extramural collaboration to amplify data accrual for rare disorders, such as CHMCF. This case series demonstrates a novel collaboration, as the idea was initiated in a private social media group of physicians and resulted in a wide collaborative effort from institutions across the United States. These same methods can be used with other rare complications to expand our knowledge base and lead to more meaningful observations from which to draw conclusions.

\section{Supplementary Video S1}

Dizygotic pregnancy with complete hydatidiform molar tissue and a viable fetus with normal placental tissue. Online content including video sequences viewable at: https://www.thieme-connect.com/products/ ejournals/html/10.1055/a-1678-3563.

\section{Conflict of Interest}

None declared.

\section{References}

1 Sebire NJ, Foskett M, Paradinas FJ, et al. Outcome of twin pregnancies with complete hydatidiform mole and healthy co-twin. Lancet 2002;359(9324):2165-2166

2 Steller MA, Genest DR, Bernstein MR, Lage JM, Goldstein DP, Berkowitz RS. Natural history of twin pregnancy with complete hydatidiform mole and coexisting fetus. Obstet Gynecol 1994;83 (01):35-42

3 Lin LH, Maestá I, Braga A, et al. Multiple pregnancies with complete mole and coexisting normal fetus in North and South America: a retrospective multicenter cohort and literature review. Gynecol Oncol 2017;145(01):88-95

4 Matsui H, Sekiya S, Hando T, Wake N, Tomoda Y. Hydatidiform mole coexistent with a twin live fetus: a national collaborative study in Japan. Hum Reprod 2000;15(03):608-611

5 Vassilakos P, Riotton G, Kajii T. Hydatidiform mole: two entities. A morphologic and cytogenetic study with some clinical consideration. Am J Obstet Gynecol 1977;127(02):167-170

6 Fishman DA, Padilla LA, Keh P, Cohen L, Frederiksen M, Lurain JR. Management of twin pregnancies consisting of a complete hydatidiform mole and normal fetus. Obstet Gynecol 1998;91(04): 546-550

7 Lee SW, Kim MY, Chung JH, Yang JH, Lee YH, Chun YK. Clinical findings of multiple pregnancy with a complete hydatidiform mole and coexisting fetus. J Ultrasound Med 2010;29(02):271-280

8 Bovicelli L, Ghi T, Pilu G, et al. Prenatal diagnosis of a complete mole coexisting with a dichorionic twin pregnancy: case report. Hum Reprod 2004;19(05):1231-1234

9 Wax JR, Pinette MG, Chard R, Blackstone J, Do , Cartin A. Prenatal diagnosis by DNA polymorphism analysis of complete mole with coexisting twin. Am J Obstet Gynecol 2003;188(04):1105-1106

10 Vejerslev LO. Clinical management and diagnostic possibilities in hydatidiform mole with coexistent fetus. Obstet Gynecol Surv 1991;46(09):577-588

11 Rajesh U, Cohn MR, Foskett MA, Fisher RA, el Zaki D. Triplet pregnancy with a coexisting complete hydatidiform mole of monospermic origin in a spontaneous conception. BJOG 2000; 107(11):1439-1442

12 Malhotra N, Deka D, Takkar D, Kochar S, Goel S, Sharma MC. Hydatiform mole with coexisting live fetus in dichorionic twin gestation. Eur J Obstet Gynecol Reprod Biol 2001;94(02):301-303

13 Zilberman Sharon N, Maymon R, Melcer Y, Jauniaux E. Obstetric outcomes of twin pregnancies presenting with a complete hydatidiform mole and coexistent normal fetus: a systematic review and meta-analysis. BJOG 2020;127(12):1450-1457

14 Sauerbrei EE, Salem S, Fayle B. Coexistent hydatidiform mole and live fetus in the second trimester: an ultrasound study. Radiology 1980;135(02):415-417

15 Ohmichi M, Tasaka K, Suehara N, Miyake A, Tanizawa O. Hydatidiform mole in a triplet pregnancy following gonadotropin therapy. Acta Obstet Gynecol Scand 1986;65(05):523-524

16 Azuma C, Saji F, Takemura M, et al. Triplet pregnancy involving complete hydatidiform mole and two fetuses: genetic analysis by deoxyribonucleic acid fingerprint. Am J Obstet Gynecol 1992;166 (02):664-667

17 Albright BB, Shorter JM, Mastroyannis SA, Ko EM, Schreiber CA, Sonalkar S. Gestational trophoblastic neoplasia after human chorionic gonadotropin normalization following molar pregnancy: a systematic review and meta-analysis. Obstet Gynecol 2020; 135(01):12-23

18 Nayeri UA, West AB, Grossetta Nardini HK, Copel JA, Sfakianaki AK. Systematic review of sonographic findings of placental mesenchymal dysplasia and subsequent pregnancy outcome. Ultrasound Obstet Gynecol 2013;41(04):366-374 
19 Jauniaux E, Brown R, Snijders RJ, Noble P, Nicolaides KH. Early prenatal diagnosis of triploidy. Am J Obstet Gynecol 1997;176 (03):550-554

20 Cohen MC, Roper EC, Sebire NJ, Stanek J, Anumba DO. Placental mesenchymal dysplasia associated with fetal aneuploidy. Prenat Diagn 2005;25(03):187-192

21 Szulman AE, Surti U. The syndromes of hydatidiform mole. I. Cytogenetic and morphologic correlations. Am J Obstet Gynecol 1978;131(06):665-671

22 Kajii T, Ohama K. Androgenetic origin of hydatidiform mole. Nature 1977;268(5621):633-634

23 Ohama K, Kajii T, Okamoto E, et al. Dispermic origin of XY hydatidiform moles. Nature 1981;292(5823):551-552

24 van de Geijn EJ, Yedema CA, Hemrika DJ, Schutte MF, ten Velden JJ. Hydatidiform mole with coexisting twin pregnancy after gamete intra-fallopian transfer. Hum Reprod 1992;7(04):568-572

25 Shahabi S, Naome G, Cobin L, et al. Complete hydatidiform mole and coexisting normal fetuses. A report of two cases with contrasting outcomes. J Reprod Med 1997;42(11):756-760

26 Shozu M, Akimoto K, Kasai T, Inoue M, Michikura Y. Hydatidiform moles associated with multiple gestations after assisted reproduction: diagnosis by analysis of DNA fingerprint. Mol Hum Reprod 1998;4(09):877-880
27 Higashino M, Harada N, Hataya I, Nishimura N, Kato M, Niikawa N. Trizygotic pregnancy consisting of two fetuses and a complete hydatidiform mole with dispermic androgenesis. Am J Med Genet 1999;82(01):67-69

28 Gray-Henry DM, Ravindranath NT, Adeghe JH. Triplet pregnancy with complete hydatidiform mole coexisting with two fetuses. J Obstet Gynaecol 1999;19(01):80-81

29 Amr MF, Fisher RA, Foskett MA, Paradinas FJ. Triplet pregnancy with hydatidiform mole. Int J Gynecol Cancer 2000;10(01): 76-81

30 Takagi K, Unno N, Hyodo HE, et al. Complete hydatidiform mole in a triplet pregnancy coexisting two viable fetuses: case report and review of the literature. J Obstet Gynaecol Res 2003;29(05): 330-338

31 Steigrad SJ, Robertson G, Kaye AL. Serial hCG and ultrasound measurements for predicting malignant potential in multiple pregnancies associated with complete hydatidiform mole: a report of 2 cases. J Reprod Med 2004;49(07): 554-558

32 Ko PC, Peng HH, Soong YK, Chang SD. Triplet pregnancy complicated with one hydatidiform mole and preeclampsia in a $46, \mathrm{XY}$ female with gonadal dysgenesis. Taiwan J Obstet Gynecol 2007;46 (03):276-280 